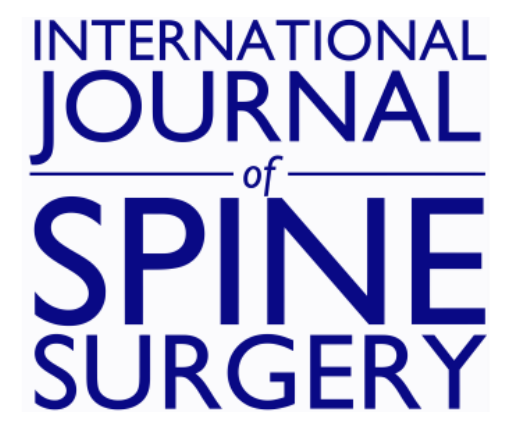

\title{
Hybrid Decompression and Fixation Technique for the Treatment of Multisegmental Cervical Spondylotic Myelopathy
}

Barón Zárate-Kalfopulos, Walter Araos-Silva, Alejandro Reyes-Sánchez, Luis Miguel Rosales-Olivarez, Armando Alpizar-Aguirre and Francisco Lopez Melendez

Int J Spine Surg 2016, 10 ()

doi: https://doi.org/10.14444/3030

http://ijssurgery.com/content/10/30

This information is current as of April 26, 2023.

Email Alerts Receive free email-alerts when new articles cite this article. Sign up at:

http://ijssurgery.com/alerts

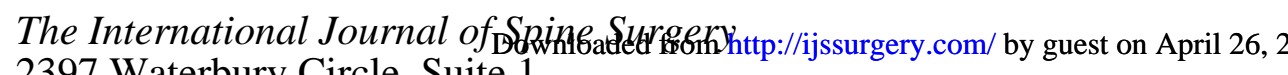
2397 Waterbury Circle, Suite 1,

Aurora, IL 60504, Phone: +1-630-375-1432 


\section{Hybrid Decompression and Fixation Technique for the Treatment of Multisegmental Cervical Spondylotic Myelopathy}

Barón Zárate-Kalfopulos MD, Walter Araos-Silva MD, Alejandro Reyes-Sánchez PhD, Luis Miguel Rosales-Olivarez MD, Armando Alpizar-Aguirre $M D$, Francisco Lopez Melendez MD

Spine Surgery Service, Instituto Nacional de Rehabilitación, México

\section{Abstract}

Background

Cervical spondilotic myelopathy (CSM) is defined as the compromise of the spinal cord due to degenerative changes of the cervical spine. It is the most common cause of spinal cord dysfunction in patients over 55 years. An early surgical management it is paramount to achieve better neurological outcome. There is still controversy regarding the appropriate surgical treatment for multisegmental CSM involving three or more levels. The hybrid decompression and fixation technique combines one or two level corpectomy and a single level discectomy in order to obtain optimum decompression and fixation in patients with multilevel cervical myelopathy

Methods

A prospective case-control study was made between 2011 and 2013. A total of 15 patients with diagnosis of CSM received surgical treatment with an anterior hybrid decompression and fixation technique procedure. Inclusion criteria were myelopathy confirmed by radiographic studies, magnetic resonance image (MRI) and electromyography.

Results

During the 2010-2013 period 15 patients were managed by hybrid decompression and fixation technique. Average age 64.8 years $\mathrm{SD} 9.4$. The follow up period was $29.6 \mathrm{SD} \pm 9.8$ months. The JOA score improved significantly to $13.8+/-1.9$ points at follow-up (paired t test, $\mathrm{P}=0.001$ ) , Nurick Scale preoperative was 3.3 and improved to 2.4 mean, was significantly (Wilcoxon signed rank test $\mathrm{p}=0.006$ ) The mean $\mathrm{C} 2-\mathrm{C} 7$ lordosis angle was $10.8^{0}+/-8.9$ before surgery, and $14.3^{\circ}+/-8.8$ at follow-up, there was no significant loss of lordosis angle between the preoperative and follow-up measurements (Wilcoxon signed rank test, $\mathrm{P}=0.149$ ); At follow-up, graft non fusion was seen in 1 patient $(7 \%, \mathrm{k}=1)$;

\section{Conclusions}

In this small number, single surgeon, prospective series the use of a single level corpectomy and an adjacent discectomy was shown to provide similar outcomes and complication rates as alternative surgical techniques. The authors thus consider this a viable surgical alternative with some perceived advantages, a low rate of complications and a high rate of spinal fusion.

Level of Evidence: IV. This study was approved by the authors' Institutional Review Board and all patients were given informed consent prior to participation in the study.

KEYWORDS: ANTERIOR CERVICAL FIXATION, ANTERIOR CERVICAL DECOMPRESSION, CERVICAL MYELOPATHY, MULTILEVEL CERVICAL STENOSIS VOLUME 10 ARTICLE 30 DOI: 10.14444/3030

\section{Introduction}

Cervical spondylotic myelopathy (CSM) is defined as spinal cord compromise caused by degenerative changes in the cervical spine. ${ }^{1} \mathrm{CSM}$ is the most common cause of spinal cord dysfunction in patients aged over 55 years. ${ }^{1,2,3} \mathrm{CSM}$ is also the most common cause of non-traumatic paraparesis and quadriparesis.

Unlike other pathologies of the spine, for which initial treatment is usually conservative, early surgical 
management of CSM is critical to ensure a good neurological outcome. ${ }^{4,5,6}$ The appropriate surgical treatment for multisegmental CSM involving three or more levels remains controversial.

A posterior approach with laminectomy or laminoplasty is considered to be a good surgical option. However, spinal cord injury, nerve root injury, kyphosis, and psudoarthrosis are among the complications of posterior cervical spine surgery. Such complications may cause pain or neurological deterioration, and re-operation may be required. ${ }^{7,9}$

The anterior approach removes most compressive lesions, features muscle-sparing dissection (minimizing postoperative pain), and allows correction and decompression of cord regions lying over kyphotic lesions. ${ }^{10}$ Such treatment is generally successful and affords a high rate of osseous fusion. However, pseudoarthrosis remains an important complication. Wang et al. ${ }^{11}$ showed that the risk of pseudoarthrosis was higher after multi-level than single-level anterior cervical discectomy and fusion (ACDF); the fusion rates after one-, two-, and three-level ACDF were $88-90 \%, 73-80 \%$, and $70 \%$, respectively. Similarly, Vaccaro et al. ${ }^{12}$ reported early reconstruction failures in $9 \%$ of patients who underwent two-level corpectomy and in 50\% of patients who underwent three-level corpectomy. The hybrid decompression and fixation technique combines one- or two-level corpectomy with single-level discectomy to optimize decompression and fixation in patients with multi-level cervical myelopathy. ${ }^{13}$ The aim of our present study was to evaluate the clinical outcomes and fusion rates afforded by the hybrid technique in patients with three-level CSM after at least two years of follow-up.

\section{Materials and Methods}

Our institutional review board approved this prospective case-control study. A total of $158 \mathrm{pa}$ tients underwent surgery after diagnosis of CSM between 2010 and 2013 in our institution. Of these, 15 underwent anterior hybrid decompression and fixation between 2011 and 2013. The 15 patients were all treated by the same surgeon and were followed up for more than 24 months. The remaining patients (143) were diagnosed with narrowed cervical spinal canals at one or two levels, and were thus not candidates for management using the hybrid decompression and fixation technique.

The inclusion criterion was myelopathy confirmed by magnetic resonance imaging (MRI) and by electromyography, In all patients Nurick scales and JOA score were made at the time of diagnosis and one year of post-surgical (Table 1, Table 2). Patients who had undergone prior cervical surgery and those whose myelopathy was not degenerative in nature were excluded. All patients underwent at least six months of nonoperative treatment.

\section{Surgical Procedure}

The levels to be decompressed and fixed were determined based on patient history, physical examination, and imaging data (Figure 1, Figure 3). All patients were managed by initial creation of a cervical anterior Smith-Robinson incision on the left side. Discectomy was performed on three degenerated discs, followed by single-level corpectomy of the vertebra that was maximally reduced, and/or was associated with severe spinal cord ventral compression induced by retrovertebral disease. Subsequently, the adjacent upper or lower intervertebral space was decompressed. To ensure that decompression was adequate, we resected the posterior longitudinal ligament to the limit of the dural sac. The vertebra was reconstructed by implanting a homologous graft from the fibula. A titanium plate of suitable length and curvature was positioned in the adjacent disc space and fixed with six screws. ${ }^{14,15}$ (Figure 2, Figure 4).

\begin{tabular}{|c|c|}
\hline $\begin{array}{l}\text { Grade } \\
0\end{array}$ & $\begin{array}{r}\text { Signs or symptoms of root involvement but without evidence of } \\
\text { spinal cord disease }\end{array}$ \\
\hline $\begin{array}{l}\text { Grade } \\
1\end{array}$ & Signs of spinal cord disease but no difficulty in walking \\
\hline $\begin{array}{l}\text { Grade } \\
2\end{array}$ & Slight difficulty in walking that did not prevent full-time employment \\
\hline $\begin{array}{l}\text { Grade } \\
3\end{array}$ & $\begin{array}{l}\text { Difficulty in walking that prevented full-time employment or the abil- } \\
\text { ity to perform all housework but that was not severe enough to re- } \\
\text { quire someone else's help to walk }\end{array}$ \\
\hline $\begin{array}{l}\text { Grade } \\
4\end{array}$ & Able to walk with someone else's help or the aid of a frame \\
\hline $\begin{array}{l}\text { Grade } \\
5\end{array}$ & Chair bound or bedridden \\
\hline
\end{tabular}




\section{Radiological Parameters}

Cervical lordosis was defined by reference to the angle formed between the lower endplate of $\mathrm{C} 2$ and the upper endplate of C7. Fusion was defined as the absence of motion between spinous processes, as evident on flexion/extension radiographs; the absence of any dark halo around grafted bone or the intervertebral cages; and/or the presence of bridging bone evident on a computed tomography (CT) scan taken after 24 months of follow-up.

Table 2. Japanese Orthopaedic Association score (JOA-score modified by Keller 1993)

\begin{tabular}{|c|c|}
\hline Motor Function & \\
\hline Paralysis & 1 \\
\hline \multicolumn{2}{|l|}{ Upper extremity } \\
\hline Fine motor function massively decreased & 2 \\
\hline Fine motor function decelerated & 3 \\
\hline Discreet weakness in hands or proximal arm & 4 \\
\hline Normal function & 5 \\
\hline \multicolumn{2}{|l|}{ Motor Function } \\
\hline Unable to walk & 1 \\
\hline \multicolumn{2}{|l|}{ Lower extremity } \\
\hline Need walking aid on flat floor & 2 \\
\hline Need handrail on stairs & 3 \\
\hline Able to walk without walking aid, but inadequate & 4 \\
\hline Normal function & 5 \\
\hline \multicolumn{2}{|l|}{ Sensory } \\
\hline \multicolumn{2}{|l|}{ Upper extremity/lower extremity/trunk } \\
\hline Apparent sensory loss & 1 \\
\hline Minimal sensory loss & 2 \\
\hline Normal function & 3 \\
\hline \multicolumn{2}{|l|}{ Bladder function } \\
\hline Urinary retention & 1 \\
\hline Severe dysfunction & 2 \\
\hline Mild dysfunction & 3 \\
\hline Normal function & 4 \\
\hline Total score & $0-17$ \\
\hline
\end{tabular}

The lower the score the more severe the deficits. Normal function $16+17$, grade 1: 12-15, grade 2: 8-11, grade 3: $0-7$.
Conventional lateral radiographs of the cervical spine (C3-C7) were analyzed to determine the Torg/ Pavlov ratio. Measurements were made at the level of the higher retrovertebral commitment, and the upper and lower levels. Each ratio was calculated by dividing the sagittal diameter of the cervical spinal canal by the sagittal diameter of the vertebral body. All measurements were independently made, twice, by

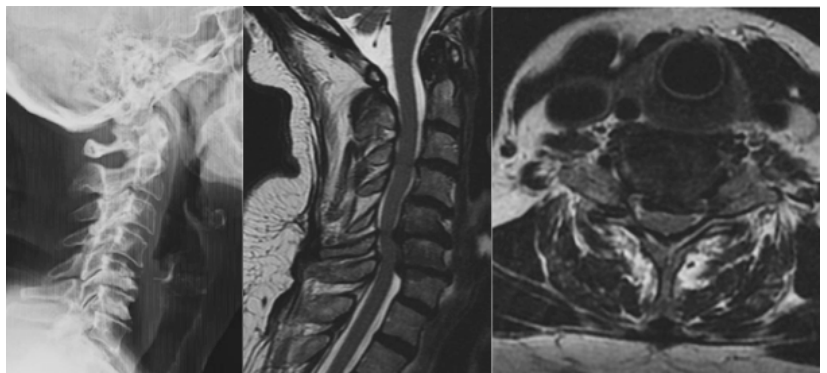

Fig. 1. A 66-year-old female patient complained of numbness of both hands and difficulty of ambulation for 7 years.: (a)X-ray lateral view of pre-operative three-level (C4-C7) CSM. segmental lordosis: $3^{\circ}$; (b) Preoperative sagittal MRI showing the presence of three-segment spinal cord compression associated with T2 signal changes (c) Preoperative axial MRI showing C4 - C5 large central herniated disc with reduction in cervical spinal canal diameter.

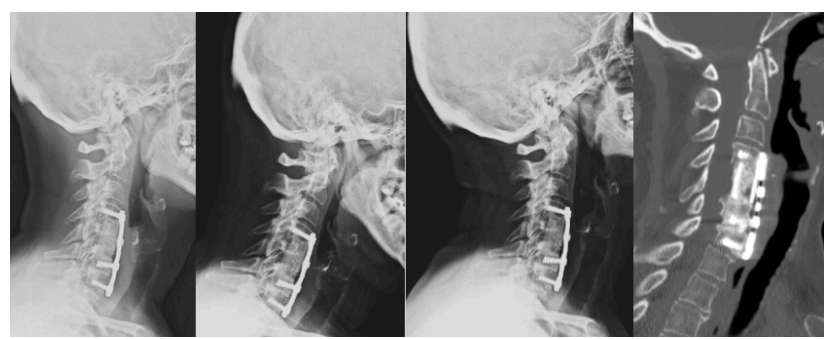

Fig. 2. Postoperative images of the same 66-year-old female patient (a) $X$-ray lateral view 6 months post-operation. Fused segmental lordosis: $10^{\circ}$; (b,c) 6 months Post-operative flexion-extension X-ray images showed that fused segments were stable; (d) 1 year postoperative sagittal reconstruction of CT scanning showed bony fusion.

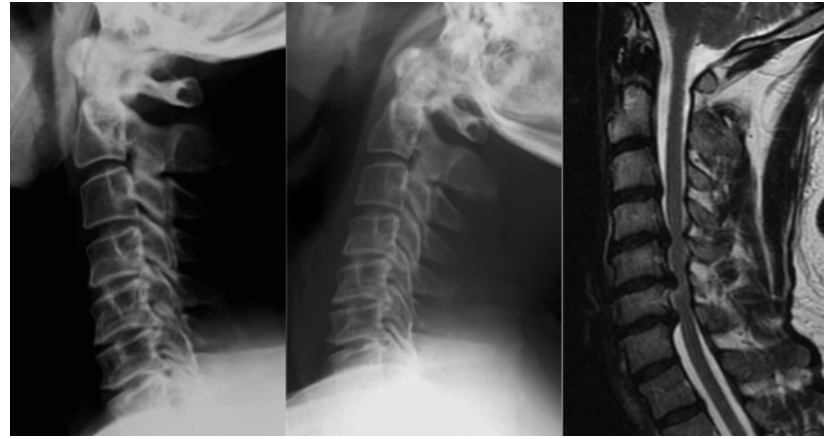

Fig. 3. 62 year old male complained of neck pain and stiffness, and difficulty of ambulation for 3 years: $(a, b) X$-ray lateral view of pre-operative three-level (C4-C7) CSM. Segmenal lordosis 10, Torg/Pavlov ratio at C6: 0.6 , (c) Preoperative sagittal MRI showing the presence of three-segment (C4-C7) spinal cord compression associated with T2 signal changes. 
two observers, without reference to prior measurements, using OsiriX software (version 5.8.5; Pixmeo Sarl, Berne, Switzerland). We considered that a value less than 0.7 was pathological..$^{16,17}$

\section{Statistical Analysis}

All statistical analyses were performed using SPSS (Statististical Package for the Social Sciences) software (v 21; SPSS Inc., Chicago IL, USA). Data were presented as the mean \pm standard deviation (SD). Shapiro-Wilk test was used to assess the distribution of the sample. Paired t-test was used for the comparison of continuous variables between pre and postoperative data; Wilcoxon signed rank test was used for non continuous variables and for non normal distribution samples, and Mann-Whitney U test was used for the non parametric distribution for independent samples. A probability value of less than 0.05 was considered significant.

\section{Results}

From 2010-2013, 158 surgical procedures were performed at our institution on patients diagnosed with CSM; 15 (9.8\%) were managed by hybrid decompression and fixation. All patients completed their followup.

\section{Clinical results}

The demographic clinical data are summarized in Table 3. Of the 15 patients, 8 were male. The average age was 64.8 years. The average blood loss was $265 \pm$ $172 \mathrm{~mL}$. The average operative time was $170 \pm 51$ $\mathrm{min}$. The follow-up period was $29.6 \pm 9.4$ months.The average preoperative JOA score was 11.4

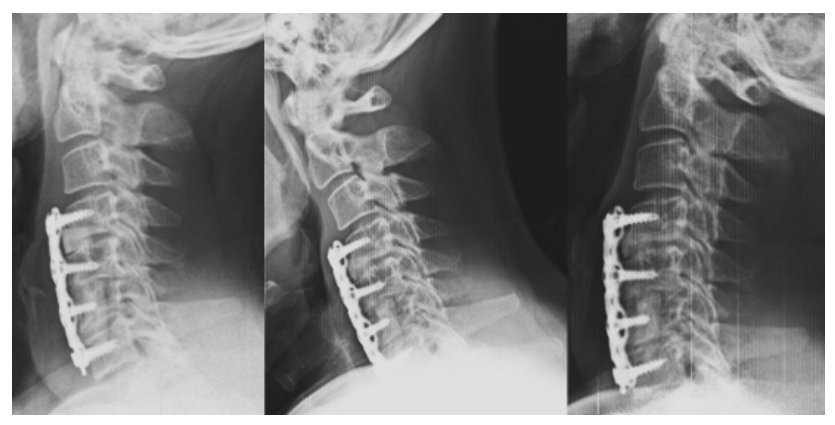

Fig. 4. Fig 4.Postoperative images of the same patient at one year follow. (a) X-ray lateral view 1 year post operation. Fused segmental lordosis $20^{\circ}$ (b, c) Rx- lateral view flexion and extension showed that all fused segment are stable. In this case an additional screw is used to secure the bone graft, obtaining good final results in relation to the fusion rate.
+/- 2.6 (mean-standard deviation [SD]). The JOA score improved significantly to $13.8+/-1.9$ points at follow-up (paired t test, $\mathrm{P}=0.001$ ), Nurick Scale preoperative was 3.3 and improved to 2.4 mean, was significantly (Wilcoxon signed rank test $\mathrm{p}=0.006$ ). The recovery rate of JOA score was $38.9 \%$ at follow up. SF-36 improved significantly in the MCS score (Table 3).

The JOA score did not significantly differ between male and female patients (Mann-Whitney $\mathrm{U}$ test, $\mathrm{P}=$ 0.281).

\section{Radiographic results}

The radiographic data are summarized in Table 4. The mean $\mathrm{C} 2-\mathrm{C} 7$ lordosis angle was $10.8^{\circ}+/-8.9$ before surgery, and $14.3^{\circ}+/-8.8$ at follow-up, there was no significant loss of lordosis angle between the preoperative and follow-up measurements (Wilcoxon

\begin{tabular}{|c|c|c|c|c|}
\hline FACTOR & PRE & $\begin{array}{r}\text { FOLLOW } \\
\text { UP }\end{array}$ & $P$ value & $\begin{array}{r}\text { STATISTICAL } \\
\text { ANALYSIS }\end{array}$ \\
\hline Sex & $\begin{array}{r}\text { Male } 8 \\
(53.3 \%), \text { fe- } \\
\text { male } 7(46.7 \%)\end{array}$ & & & NT \\
\hline $\begin{array}{l}\text { Age at } \\
\text { surgery } \\
\text { (years) }\end{array}$ & 64.8, SD 9.4 & & & NT \\
\hline $\begin{array}{l}\text { Blood loss } \\
\text { (cc) }\end{array}$ & & $\begin{array}{r}264.7 \\
\mathrm{SD} \pm \\
172.5\end{array}$ & & NT \\
\hline $\begin{array}{l}\text { Operation } \\
\text { time (min- } \\
\text { utes) }\end{array}$ & & $\begin{array}{r}178.3, \mathrm{SD} \\
\pm 55.3\end{array}$ & & NT \\
\hline $\begin{array}{l}\text { Follow-up } \\
\text { period } \\
\text { (months) }\end{array}$ & & $\begin{array}{r}29.6, \mathrm{SD} \\
\pm 9.8\end{array}$ & & NT \\
\hline $\begin{array}{l}\text { JOA score } \\
\text { (points) }\end{array}$ & $11.4, \mathrm{SD} \pm 2.6$ & $\begin{array}{r}13.8, \mathrm{SD}_{ \pm} \\
1.9\end{array}$ & $\begin{array}{r}0.001(\mathrm{CI} \\
95 \% 1.1-3.7)\end{array}$ & paired $t$ test \\
\hline $\begin{array}{l}\text { JOA Recov- } \\
\text { ery rate }(\%)\end{array}$ & & $\begin{array}{r}38.9 \% \\
\mathrm{SD} \pm 38.5\end{array}$ & NT & NT (1) \\
\hline $\begin{array}{l}\text { Nurick } \\
\text { Scale }\end{array}$ & $3.3, \mathrm{SD} \pm 1$ & $\begin{array}{r}2.4, \mathrm{SD} \pm \\
0.9\end{array}$ & 0.006 & $\begin{array}{r}\text { Wilcoxon } \\
\text { signed rank test }\end{array}$ \\
\hline SF-36 MCS & $35.8, \mathrm{SD} \pm 9.7$ & $\begin{array}{r}44.5, \mathrm{SD} \\
\pm 13.9\end{array}$ & $\begin{array}{r}0,049(\mathrm{CI} \\
95 \% 0.04- \\
17.29)\end{array}$ & paired $t$ test \\
\hline SF-36 PCS & $33.3, \mathrm{SD} \pm 13.8$ & $\begin{array}{r}35.5, \mathrm{SD} \\
\pm 9.5\end{array}$ & $\begin{array}{r}0.644(\mathrm{CI} \\
95 \%-7.6- \\
11.9)\end{array}$ & paired $t$ test \\
\hline
\end{tabular}


signed rank test, $\mathrm{P}=0.149$ ); At follow-up, graft non fusion was seen in 1 patient $(7 \%, \mathrm{k}=1)$; but JOA scores at follow-up did not differ significantly between patients who had fusion (13.6 points) and those who had non fusion (16.0 points) (Mann-Whitney U test, $\mathrm{P}=0.267)$. Allograft subsidence $>2 \mathrm{~mm}$ was observed in $2(13.3 \%)$ patients, but has no significance in results in JOA score at follow up (Mann-Whitney $\mathrm{U}$ test, $\mathrm{P}=1$ ).

\section{Discussion}

The surgical approach of choice for management of CSM remains controversial. The approach may be anterior (multiple discectomies, corpectomies) or posterior (laminoplasty, laminectomy). However, the anterior approach, with multiple corpectomies and/ or discectomies, is most widely used. Multiple-level discectomies reduce trans-surgical bleeding and improve postoperative lordosis, as noted by Song et al. ${ }^{18}$ and Lin et al. ${ }^{19}$ However, cervical corpectomy is necessary when ventral spinal cord disease induced by retrovertebral compression is evident; this affords good neurological recovery, as mentioned by Jiang et al. ${ }^{20}$ Performance of corpectomies at more than three levels may cause complications such as graft extrusion or collapse, fracture, or pseudoarthrosis. ${ }^{11,12}$

Outcomes after hybrid decompression and segmental fixation have been previously reported. Ashkenazy et al. ${ }^{21}$ developed the hybrid decompression fixation technique to manage multi-level myelopathy. Guo et al. ${ }^{22}$ evaluated 53 patients with three-level cervical spondylosis who underwent anterior hybrid decompression and segmental fixation, with placement of titanium mesh and a polyetheretherketone (PEEK) cage with a locking plate. At an average follow-up time of 37.3 months, bone fusion was observed in all

Table 4. Radiological Outcomes.
\begin{tabular}{|l|r|r|r|r|}
\hline FACTOR & PRE & $\begin{array}{r}\text { FOLLOW } \\
\text { UP }\end{array}$ & P & $\begin{array}{r}\text { STATISTICAL } \\
\text { ANALYSIS }\end{array}$ \\
\hline cervical lordosis & $\begin{array}{r}10.8, \\
\text { SD } \pm \\
8.9\end{array}$ & $\begin{array}{r}14.3, \mathrm{SD} \\
\pm 8.8\end{array}$ & $\begin{array}{r}0.116(\mathrm{CI} \\
95 \%-1.61-\end{array}$ & paired t test \\
\hline Torg Ratio (mean) & 0.66 & & & NT \\
corpectomy level & & & & NT \\
\hline Fusion rate (\%) & & $93 \%$ & & \\
\hline
\end{tabular}
NT: Not testable; SD: Standard Deviation; Cl: Confidence intervals.

patients. The JOA score improved from 8.1 to 13.1, and cervical lordosis from 9.7 to $17.7^{\circ}$. Postoperative complications included C5 palsy, cerebrospinal fluid leakage, hematoma, and titanium mesh subsidence.

Odate et al. ${ }^{13}$ in 2009 , and Liu et al..$^{14}$ in 2013 , evaluated 81 and $28 \mathrm{CSM}$ patients at 2 and 4 years postoperatively, respectively, who had undergone multilevel decompression. When multiple corpectomy and hybrid fixation were compared, the latter method afforded several advantages. Less bone graft was required and the risk of reconstruction and incidence of C5 paralysis were both lower (3\% vs. $17 \%$ rate of paralysis). The JOA scores were 50-55\% higher and the lordosis correction $7^{\circ}$ greater.

On the JOA scale, out patients improved by $42.8 \%$; the Nurick score increased in all patients; and the lordosis correction averaged $4^{\circ}$.

We did not record any instance of C5 palsy; the average incidence of such palsy after cervical decompression has been reported to be $4.6 \%{ }^{23}$ Odate et al. performed a comparative retrospective study and found that the incidence of $\mathrm{C} 5$ palsy was $17 \%$ in 42 patients of a corpectomy group and 3\% in 39 patients of a hybrid group. ${ }^{13}$ The absence of C 5 palsy in our study may be attributable to our relatively small number of patients.

Graft integration was assessed by $\mathrm{CT}^{24}$ featuring sagittal and axial reconstruction, which is more accurate than X-ray examination. The extent of graft integration was $93 \%$. Allograft subsidence with loss of superior fixation was observed in one patient. However, he reported no neck pain and refused revision surgery. Kotil et al. ${ }^{25}$ studied 25 patients with multilevel CSM treated via two-level corpectomy and iliac crest fusion; the fusion rate was $100 \%$ and the clinical results were good. Similar to what we found, Odate et al. reported a $95 \%$ fusion rate using the hybrid decompression and fixation technique. ${ }^{13}$

Our study had several limitations. Although the work was prospective in nature, we were unable to perform a randomized control trial comparing the hybrid technique with posterior techniques such as laminectomy and fusion. Also, our sample size was 
small because multi-level cervical myelopathy is not clinically common.

\section{Conclusions}

In this small number, single surgeon, prospective series the use of a single level corpectomy and an adjacent discectomy was shown to provide similar outcomes and complication rates as alternative surgical techniques. The authors thus consider this a viable surgical alternative with some perceived advantages, a low rate of complications and a high rate of spinal fusion.

The exact role of this surgical modification to treat cervical myelopathy will require multiple future and larger series by other investigators to reproduce these results and elucidate subgroups that would benefit from a particular surgical technique.

\section{References}

1. Young WF. Cervical spondylotic myelopathy: A common cause of spinal cord dysfunction in older persons. Am Fam Physician. 2000 Sep 1;62(5):1064-1073.

2. Baron EM, Young WF.. Cervical spondylotic myelopathy: A brief review of its pathophysiology, clinical course, and diagnosis. Neurosurgery. 2007 Jan;60(Suppl 1):S35-S41.

3. William E. Krauss M.D., Michael J. Ebersold, M.D., Lynn M. Quast, R.N. Cervical Spondylotic Myelopathy; Surgical Indications and Technique. Contemporary Neurosurgery. 1998 May;20(10):1-5. 4. Vitzthum HE, Dalitz K. Analysis of five specific scores for cervical spondylogenic myelopathy. Eur Spine J. 2007 Dic;16(12):2096-2103.

5. Boogaarts HD, Bartels RH. Prevalence of cervical spondylotic myelopathy. Eur Spine J. 2015 Apr;24(Suppl 2):S139-S141.

6. Inturias C., Marcelo O; Arauco R. Cervical spondylotic myelopathy and their Study in Magnetic Resonance Imaging [in Spanish] Rev. chil. reumatol. 2003; 19(1):39-46.

7. Lee CH, Lee J, Kang JD, Hyun SJ, Kim KJ, Jahng TA, Kim HJ. Laminoplasty versus laminectomy and fusion for multilevel cervical myelopathy: a meta- analysis of clinical and radiological outcomes. J Neurosurg Spine. 2015 Jun;22(6):589-595.

8. Edwards CC, Heller JG, Murakami H. Corpectomy Versus Laminoplasty for Multilevel Cervical Myelopathy. Spine. 2002 Jun 1;27(11):1168-1175.

9. Ikenaga M, Shikata J, Tanaka C. Anterior corpectomy and fusion with fibular strut grafts for multilevel cervical myelopathy. J Neurosurg Spine. 2005 Aug; 3(2):79-85.

10. Rhee JM, Basra S: Posterior surgery for cervical myelopathy; laminectomy, laminectomy with fusion and laminoplasty. Asian Spine J. Dic; 2(2):114-126.

11. Wang, J.C, McDonough PW, Endow KK, Delamarter RB. Increased fusion rates with cervical plating for two-level anterior cervical discectomy and fusion. Spine. 2005 Jan;25(1):41-45.

12. Vaccaro AR, Falatyn SP, Scuderi GJ, McGuire RA, Singh K, Garfin SR. Early failure of long segment anterior cervical plate fixation. J Spinal Disord. 1998 Oct;11(5):410-415.

13. Odate $S$, Shikata J, Kimura H, Soeda T. Hybrid Decompression and Fixation Technique Versus Plated Three-vertebra Corpectomy for Foursegment Cervical Myelopathy: Analysis of 81 Cases With a Minimum 2-year Follow-up. J Spinal Disord Tech. 2013 Nov 8. [Epub ahead of print].

14. Liu Y, Yu KY, Hu JH. Hybrid decompression technique and two-level corpectomy are effective treatments for three-level cervical spondylotic myelopathy. J Zhejiang Univ Sci B. 2009 Sep; 10(9):696-701.

15. Liu Y, Hou Y, Yang L, Chen H, Wang X, Wu X, Gao R, Wang C, Yuan W. Comparison of 3 Reconstructive Techniques in the Surgical Management of Multilevel Cervical Spondylotic Myelopathy. Spine. 2013 Nov 1;37(23):1450-1458.

16. Yue WM, Tan SB. The Torg-Pavlov ratio in cervical spondylotic myelopathy: a comparative study between patients with cervical spondylotic myelopathy and a nonspondylotic, nonmyelopathic population. Spine. 2001 Aug 15;26(16):1760-4.

17. Aebli N, Wicki AG. The Torg-Pavlov ratio for the prediction of acute spinal cord injury after a minor trauma to the cervical spine. Asian Spine J. 2015 Feb;9(1):22-9

18. Song KJ, Lee KB. Efficacy of multilevel anterior cervical discectomy and fusion versus corpectomy 
and fusion for multilevel cervical spondylotic myelopathy: a minimum 5-year follow-up study. Eur Spine J. 2012 Aug;21(8): 1551-7.

19. Lin Q, Zhou X, Wang X, Cao P, Tsai N, Yuan $\mathrm{W}$. A comparison of anterior cervical discectomy and corpectomy in patients with multilevel cervical spondylotic myelopathy. Eur Spine J. 2012;21:47481.

20. Jiang SD, Jiang LS, Dai LY. Anterior cervical discectomy and fusion versus anterior cervical corpectomy and fusion for multilevel cervical spondylosis: a systematic review. Arch Orthop Trauma Surg. 2012;132:155-61.

21. Ashkenazi E, Smorgick Y, Rand N, Milligram MA, Mirovsky Y, Floman Y. Anterior decompression combined with corpectomies and discectomies in the management of multilevel cervical myelopathy: a hybrid decompression and fixation technique. J Neurosurg Spine. 2005 Sep;3(3):205-9.

22. Guo Q, Ni B, Zhou F, Lu X, Yang J, Chen J, Yu $\mathrm{Y}, \mathrm{Zhu} \mathrm{L}$. Anterior hybrid decompression and segmental fixation for adjacent three-level cervical spondylosis. Arch Orth Trauma Surg. 2001 May;131(5):631-636.

23. Sakaura H, Hosono N, Mukai Y, Ishii T, Yoshikawa H. C5 Palsy after Decompression Surgery for Cervical Myelopathy; Spine. 2003 Nov 1;28(21):2447-2451.

24. Epstein NE, Silvergleide RS. Documenting Fusion Following Anterior Cervical Surgery: A Comparison of Roentgenogram Versus Two-Dimensional Computed Tomographic Findings. Journal of Spinal
Disorders \& Techniques. 2003 Jun;16(3):243-247. 25. Kotil K, Tari R. Two level cervical corpectomy with iliac crest fusion and rigid plate fixation: a retrospective study with a three-year follow-up. Turkish Neurosurgery. 2011;21(4):606-12.

26. Edwards CC, Heller JG. Posterior Approaches for the Surgical Treatment of Multilevel Cervical Spondylotic Myelopathy. Contemporary Spine Surgery. 2002 Jan;3:1-7.

27. Singh K, Vaccaro AR, Kim J, Lorenz EP, Lim $\mathrm{TH}$, An HS. Enhancement of stability following anterior cervical corpectomy: a biomechanical study. Spinesong. 2004;29:845-9.

\section{Disclosures and COI}

All authors report no relevant financial disclosures or conflicts of interest.

\section{Corresponding Author}

Barón Zárate-Kalfopulos MD, Avenida México Xochimilco \#289, Colonia Arenal de Guadalupe, Delegación Tlalpan, 14389 México Distrito Federal, México. bzarate@inr.gob.mx.

Published 31 August 2016.

This manuscript is generously published free of charge by ISASS, the International Society for the Advancement of Spine Surgery. Copyright @ 2016 ISASS. To see more or order reprints or permissions, see http://ijssurgery.com. 